WISSENSCHAFTSZENTRUM BERLIN FÜR SOZIALFORSCHUNG

SOCIAL SCIENCE RESEARCH

CENTER BERLIN

Johannes Münster

Lobbying Contests with Endogenous Policy Proposals

SP || $2005-11$

May 2005

ISSN Nr. $0722-6748$

Research Area

Markets and Political Economy

Research Unit

Market Processes and Governance
Forschungsschwerpunkt

Markt und politische Ökonomie

Abteilung

Marktprozesse und Steuerung 
Zitierweise/Citation:

Johannes Münster, Lobbying Contests with Endogenous

Policy Proposals, Discussion Paper SP II 2005 - 11,

Wissenschaftszentrum Berlin, 2005.

Wissenschaftszentrum Berlin für Sozialforschung gGmbH,

Reichpietschufer 50, 10785 Berlin, Germany, Tel. (030) 25491 - 0

Internet: www.wz-berlin.de 


\section{Lobbying Contests with Endogenous Policy Proposals}

by Johannes Münster *

Lobbyists choose what to lobby for. If they can precommit to certain policy proposals, their choice will have an influence on the behavior of opposing lobbyists. Hence lobbyists have an incentive to moderate their policy proposals in order to reduce the intensity of the lobbying contest. This logic has been explored in a number of recent papers. I reconsider the topic with a perfectly discriminating contest. With endogenous policy proposals, there is a sub-game perfect equilibrium where the proposals of the lobbyists coincide and maximize joint welfare; moreover, this equilibrium is the only one that survives repeated elimination of dominated strategies. Hence there is no rent dissipation at all. A politician trying to maximize lobbying expenditures would prefer an imperfectly discriminating contest.

Keywords: Interest groups, endogenous lobbying targets, voluntary restraint, polarization

JEL Classification: D72

\section{ZUSAMMENFASSUNG}

\section{Lobby Wettkämpfe mit endogenen Politikvorschlägen}

Wenn eine Lobbygruppe sich bindend auf einen Politikvorschlag festlegen kann, bevor sie in einen Lobbywettkampf mit einer anderen Gruppe tritt, dann hat sie einen Anreiz zu strategischer Zurückhaltung: Kommt sie der anderen Gruppe ein wenig entgegen, so entschärft das den Wettkampf zwischen den Gruppen. Diese Idee ist kürzlich in einer Reihe von Aufsätzen untersucht worden. Ich trage zu dem Thema bei, indem ich einen vollständig diskriminierenden Wettkampf als Modell für den Lobbywettkampf verwende. Es existiert ein teilspielperfektes Gleichgewicht, in dem beide Lobbygruppen dieselbe Politik vorschlagen, und zwar diejenige, die ihre gemeinsame Wohlfahrt maximiert. Dieses Gleichgewicht ist das einzige, das bei wiederholter Elimination dominierter Strategien übrig bleibt. Folglich kämpfen die Gruppen nicht wirklich, und es gibt keine Rentendissipation. Ein Politiker, der versucht, die Lobbyausgaben zu maximieren, würde einen unvollständig diskriminierenden Wettkampf vorziehen.

\footnotetext{
* I want to thank Johan Lagerlöf, participants at the European Public Choice Society Meeting in Berlin 2004, and two anonymous referees for helpful comments and suggestions. The usual caveat applies. Financial support from the Deutsche Forschungsgemeinschaft through SFB/TR 15 is gratefully acknowledged.
} 


\section{Introduction}

Lobbyists choose what to lobby for. If they can precommit to certain policy proposals, their choice will have an influence on the behavior of opposing lobbyists. This leads to a moderation in the policy proposals, as has been shown by a number of recent papers. ${ }^{1}$ The most thorough study of this effect is Epstein and Nitzan (2004). They study a two stage game with two interest groups, where in stage one policy proposals are chosen, and in stage two the interest groups engage in a lobbying contest about the proposed policies. Epstein and Nitzan show that, in equilibrium, an interest group will not propose its most preferred policy. Instead, the groups will moderate their proposals.

The intuition for this result is as follows. Suppose policy proposals can be chosen from $R$. The ideal point of group one is 0 , the ideal point of group two is 1 , and payoffs are strictly monotonic over $[0,1]$. If interest group one moderates its policy proposal from 0 to some 'small' $\varepsilon>0$, there are two effects. On the one hand, the group's payoff from winning the contest is lowered. On the other hand, the incentive lobbying group two has to lobby for its own policy proposal is reduced, since its payoff from losing the contest has increased. This makes group two less aggressive, which benefits group one. The first (negative) effect is a second order one if the moderation starts from group one's ideal point where the first-order condition holds. However, the moderation has a first order effect on the aggressiveness of the opposing group, so the second (positive) effect dominates. Therefore, the group gains from moderating its proposal. In equilibrium, there is strategic restraint.

On the other hand, Epstein and Nitzan show that the equilibrium policy proposals do not coincide (see their proposition 2). As I will show, this is due to the assumption that the contest is imperfectly discriminating. ${ }^{2}$

The purpose of this note is to reconsider strategic restraint in a perfectly

\footnotetext{
${ }^{1}$ Leidy (1994) studies a monopolist facing a consumer opposition and shows that the monopolist has an incentive to self-regulate to produce a higher quantity. Epstein and Nitzan (2002) reconsider the true social cost of monopoly taking this effect into account, and study applications to immigration policy (2003). Aidt (2002) has a related result concerning strategic nonparticipation.

${ }^{2}$ All the papers cited in footnote 1 share this assumption.
} 
discriminating contest. The two types of contest differ in the relationship assumed between the size of the lobbying expenditures and the probability of winning the contest. In a perfectly discriminating contest a player who spends more than his opponent wins with probability one, so small differences are decisive, whereas in an imperfectly discriminating contest the probability that a given group wins is a continuous function of the lobbying expenditures. ${ }^{3}$ The perfectly discriminating contest is an important tool in the study of lobbying contests [see, among others, Hillman and Riley (1989), Ellingsen (1991), Baye et al. (1993 and 1996) with further references, Che and Gale (1998)] and has been applied in other contexts as well [e.g. Konrad (2000a and 2000b)]. Hence it is interesting to see how results change if we assume a perfectly discriminating contest.

I show that the incentives for strategic restraint are even stronger with a perfectly discriminating contest. Policy proposals will coincide in the only subgame perfect equilibrium that survives iterated elimination of dominated strategies. The policy proposals maximize the joint welfare of the two lobbying groups. Results are thus quite different in the case of a perfectly discriminating contest. My paper also sheds new light on rent dissipation: since the lobbying groups propose the same policy, they do not spend anything on lobbying. Hence there is no rent dissipation at all.

The type of a lobbying contest is often viewed as largely determined by the political culture and laws. However, as Che and Gale (1997) point out, it is also possible to think of the type of a contest as chosen by a politician who has to make a decision about the issue at stake. While the politician cannot auction off her decision openly, she can consistently decide in favour of the lobbying group that makes the highest expenditures, and so create a perfectly discriminating contest. On the other hand, the politician can create an imperfectly discriminating contest by introducing some randomness into the determination of the winner. She could randomize literally. More importantly, as O'Keefe, Viscusi and Zeckhauser (1984) argue, the politician

\footnotetext{
${ }^{3}$ In the language of auction theory, a completely discriminating contest is a first price all pay auction. The lottery model of Tullock $(1975,1980)$, in which the probability that a given lobby group will win is proportional to its relative expenditure, is a well known special case of an imperfectly discriminating contest.
} 
can choose how precisely she monitors the lobbying expenditures. If she is not completely informed about all the expenditures, then, from the point of view of the lobbying groups, there is again some randomness in the determination of the winner: spending more than the opposing group does not ensure victory, because the politician might fail to notice.

What type of contest would the politician prefer? This, of course, depends on her objectives. If her aim is to maximize lobbying expenditures because she can appropriate part of them, she would prefer an imperfectly discriminating contest. In this respect, my paper provides imperfectly discriminating contests with a microfoundation. On the other hand, a benevolent social planner who wants to minimze rent dissipation would prefer the perfectly discriminating contest.

My paper is related to Che and Gale (1997) and Fang (2002) who compare the lottery model with the perfectly discriminating contest. However, these papers do not study endogenous policy proposals.

\section{The model}

There are two interest groups, $i=1,2$. Following Epstein and Nitzan (2004) I treat each group as a unified actor and abstract from free riding within the group. In stage one of the game, the groups simultaneously and independently choose their policy proposals $y_{i} \in R$. Their preferences for policies are given by utility functions $u_{i}: R \rightarrow R$ that measure the monetary equivalent of a policy being enacted. The ideal point of group one is 0 , the ideal point of group two is 1 . The utility functions are strictly monotonic over $[0,1]$. Further, I assume that there is a unique policy

$$
y^{*}=\arg \max _{y \in R}\left(u_{1}(y)+u_{2}(y)\right)
$$

that maximizes joint welfare of the two lobbying groups.

After observing their rival's policy proposal, in stage two of the game the interest groups choose lobbying outlays $x_{1}$ and $x_{2}$. The group that chooses the higher outlay wins the lobbying contest and its policy proposal is enacted. 
Ties are broken randomly. The groups are risk neutral, and therefore the payoff $v_{i}$ of group $i=1,2$ is

$$
v_{i}=\left\{\begin{array}{cl}
u_{i}\left(y_{i}\right)-x_{i}, & \text { if } x_{i}>x_{j} \\
u_{i}\left(y_{j}\right)-x_{i}, & \text { if } x_{i}<x_{j} \\
\frac{1}{2}\left(u_{i}\left(y_{i}\right)+u_{i}\left(y_{j}\right)\right)-x_{i}, & \text { if } x_{i}=x_{j}
\end{array}\right.
$$

\section{Analysis of the model}

Consider the contest in stage two. Define

$$
s_{i}\left(y_{i}, y_{j}\right):=u_{i}\left(y_{i}\right)-u_{i}\left(y_{j}\right)
$$

This is the stake that group $i$ has in the contest. Using this notation we get

$$
v_{i}=\left\{\begin{array}{cl}
s_{i}\left(y_{i}, y_{j}\right)-x_{i}+u_{i}\left(y_{j}\right), & \text { if } x_{i}>x_{j}, \\
-x_{i}+u_{i}\left(y_{j}\right), & \text { if } x_{i}<x_{j}, \\
\frac{1}{2} s_{i}\left(y_{i}, y_{j}\right)-x_{i}+u_{i}\left(y_{j}\right), & \text { if } x_{i}=x_{j} .
\end{array}\right.
$$

In contrast to a standard all pay auction with valuations of the prize given by $s_{1}$ and $s_{2}$, here $s_{1}$ and $s_{2}$ can be negative. Further, in the payoff functions that describe the standard all pay auction there is no term corresponding to the $u_{i}\left(y_{j}\right)$ in equation (4) - but, since $u_{i}\left(y_{j}\right)$ is constant in stage two of the game, this is not an important difference.

Suppose for the moment that $s_{1}$ and $s_{2}$ are both non-negative. That is, each group prefers its own proposal to the proposal of its rival. The properties of the equilibrium (which is in mixed strategies and unique) of the resulting contest in stage two are well known ${ }^{4}$, so I will only note one fact which is important here. In the equilibrium, the expected utility of group $i$ is equal

\footnotetext{
${ }^{4}$ See Hillman and Riley (1989); Baye et al. (1996); and the textbook of Hirshleifer and Riley (1992), Chapter 10.
} 
$E\left(v_{i}\left(y_{i}, y_{j}\right)\right)=\left\{\begin{array}{cl}s_{i}\left(y_{i}, y_{j}\right)-s_{j}\left(y_{j}, y_{i}\right)+u_{i}\left(y_{j}\right), & \text { if } s_{i}\left(y_{i}, y_{j}\right)>s_{j}\left(y_{j}, y_{i}\right) \geq 0 \\ u_{i}\left(y_{j}\right), & \text { if } s_{j}\left(y_{j}, y_{i}\right) \geq s_{i}\left(y_{i}, y_{j}\right) \geq 0 .\end{array}\right.$

In some subgames of the model, both groups prefer the proposal of the other group. ${ }^{5}$ Then they choose $x_{1}=x_{2}=0$. Therefore,

$$
E\left(v_{i}\left(y_{i}, y_{j}\right)\right)=\frac{1}{2}\left(u_{i}\left(y_{i}\right)+u_{i}\left(y_{j}\right)\right), \text { if } s_{i}\left(y_{i}, y_{j}\right)<0 \text { and } s_{j}\left(y_{j}, y_{i}\right)<0 \text {. }
$$

However, as we will see, these subgames will never be reached in equilibrium.

Consider now the choice of policy proposals in stage one of the game.

Lemma 1 For group 1 (2) each policy proposal $y_{1}>y^{*}\left(y_{2}<y^{*}\right)$ is strictly dominated by $y^{*}$.

Proof. See Appendix.

Lemma 1 says that a group will never propose a policy that is closer to the ideal point of the other group than $y^{*}$. The following proposition shows that, in every subgame perfect Nash equilibrium, at least one group will propose $y^{*}$.

Proposition 1 In every subgame perfect Nash equilibrium of the game, at least one group (call it $i$ ) proposes the policy $y^{*}$ that maximizes the joint welfare of the two groups. The other group $j$ is indifferent between all proposals $y_{j} \in\left\{y \mid u_{j}(y) \geq u_{j}\left(y^{*}\right)\right\}$.

Proof. Suppose to the contrary that $y_{1} \neq y^{*} \neq y_{2}$ in a subgame perfect equilibrium. Then by the previous lemma, $y_{1}<y^{*}<y_{2}$. But then it follows from equation (5) and the fact that $\arg \max _{y}\left(s_{2}\left(y, y_{1}\right)-s_{1}\left(y_{1}, y\right)\right)=y^{*}$ that the unique best reply of group 2 to $y_{1}$ is to propose $y^{*}$, a contradiction.

It follows that in any subgame perfect equilibrium at least one group proposes $y^{*}$. Say $y_{i}=y^{*}$. Then, by equation (5), $E\left(v_{j}\left(y_{j}, y^{*}\right)\right)=u_{j}\left(y^{*}\right)$ for all $y_{j} \in\left\{y \mid u_{j}(y) \geq y^{*}\right\}$.

\footnotetext{
${ }^{5}$ Note that $s_{i}\left(y_{i}, y_{j}\right)<0$ if and only if $s_{j}\left(y_{j}, y_{i}\right)<0$.
} 
The intuition behind proposition 1 is as follows. In the perfectly discriminating contest in stage two, expected utility in equilibrium depends on the difference in stakes. There are two ways in which a group $i$ influences the difference in stakes by its choice of $y_{i}$. First, its stake $s_{i}$ increases linearly in the utility $u_{i}\left(y_{i}\right)$ it gets if it wins the contest. Second, the stake $s_{j}$ of the rival group decreases linearly in the utility $u_{j}\left(y_{i}\right)$ the group $j$ gets if group $i$ wins the contest. The two ways are equally important. Therefore, to maximize the difference in stakes, group $i$ should choose $y_{i}$ so as to maximize the sum of its own utility $u_{i}\left(y_{i}\right)$ and the utility $u_{j}\left(y_{i}\right)$ of its rival. More formally, since

$$
\begin{aligned}
s_{i}\left(y_{i}, y_{j}\right)-s_{j}\left(y_{j}, y_{i}\right) & =u_{i}\left(y_{i}\right)+u_{j}\left(y_{i}\right)-\left(u_{i}\left(y_{j}\right)+u_{j}\left(y_{j}\right)\right)= \\
& =u_{i}\left(y_{i}\right)+u_{j}\left(y_{i}\right)+\text { terms independent of } y_{i}
\end{aligned}
$$

maximizing the difference in stakes over $y_{i}$ amounts to maximizing the joint welfare of both groups.

Proposition 1 implies that there is a subgame perfect equilibrium of the model with $y_{1}=y_{2}=y^{*}$. But there are many subgame perfect equilibria. How should we select the most sensible? Note that stage one of the game is solvable by iterated elimination of dominated strategies. ${ }^{6}$ Lemma 1 allows us to eliminate all strategies involving $y_{j}$ with $u_{j}\left(y_{j}\right)<u_{j}\left(y^{*}\right)$ for $j=1,2$. But, given that $j$ will never play such a strategy, it is a weakly dominant strategy of $i$ to propose $y^{*}$ : if $y_{j} \neq y^{*}$, then $y_{i}=y^{*}$ is the unique best reply; and if $y_{j}=y^{*}$, then $E\left(v_{i}\left(y_{i}, y_{j}\right)\right)=u_{i}\left(y^{*}\right)$ for all $y_{i}$ except those eliminated by lemma 1 . This proves

Proposition 2 There is a unique equilibrium of the reduced game given in equations (5) and (6) that survives iterated elimination of dominated strategies. In this equilibrium, both groups propose $y^{*}$.

Because of this proposition, we should expect $y_{1}=y_{2}=y^{*}$. It should

\footnotetext{
${ }^{6}$ Simply focussing on equilibria in undominated strategies has not much bite here. For example, if group one chooses $y_{1}=1$, then the best reply of group two is $y_{2}=1$. Therefore, proposing one's own ideal point is not a dominated strategy. On the other hand, proposing $y^{*}$ is not dominated either.
} 
be emphasized that this result is not based on any form of tacit collusion. Rather, it is driven by the fact that a group can only lose, and never win, from deviating from the policy proposal $y^{*}$, given that the other group doesn't play a strictly dominated strategy.

Since the two groups propose the same policy, they don't spend anything in the lobbying contest in stage two. Therefore, there is no rent dissipation at all. This contrasts with the case of an imperfectly discriminating contest studied by Epstein and Nitzan (2004). In their model, it always pays to deviate at least slightly from the policy proposal of the other interest group. In equilibrium, the two groups do not propose the same policy, and spend some positive amount on lobbying in stage two of the game.

This difference in findings is due to the nature of the contest. In an imperfectly discriminating contest, the group that chooses the higher lobbying outlay doesn't necessarily win. There is some "noise" in the determination of the winner, and winning probabilities are continuous functions of the lobbying outlays. The difference is similar to the difference between a Downsian median voter model (where winning probabilities are discontinuous and policy proposals coincide) and a probabilistic voting model (where there is some noise in the determination of the winner and policy proposals often diverge ${ }^{7}$ ).

As argued in the introduction, one can view the nature of the contest as a choice variable of a politician who has to decide over the issue at stake. What type of contest would a politician prefer, if she wanted to maximize lobbying expenditures? When policy proposals are endogenous, lobbying expenditures are positive with an imperfectly discriminating contest, but they are zero if the contest is perfectly discriminating. Therefore the politician would never choose a perfectly discriminating contest. Summing up, we have

Corollary 1 When policy proposals are endogenous,

a) there is no rent dissipation in a perfectly discriminating contest,

b) a politician who wants to maximize lobbying expenditures always prefers an imperfectly discriminating contest to a perfectly discriminating one.

It is interesting to compare this with the usual lobbying model where

\footnotetext{
${ }^{7}$ See, for example, Calvert (1985), theorem 5.
} 
policy proposals are exogenous. If the stakes of the lobbying groups are symmetric, then, with exogenous proposals, rent dissipation is complete in the perfectly discriminating contest, but incomplete in the imperfectly discriminating one. The politician prefers the perfectly discriminating contest. Surprisingly, the corollary shows that, with endogenous policy proposals, it is just the other way round: there is no rent dissipation in the perfectly discriminating contest, and it is never optimal for the politician to choose the perfectly discriminating contest, even if the lobbying groups are symmetric. ${ }^{8}$

\section{Conclusion}

This paper considered the strategic choice of policy proposals in completely discriminating contests. In equilibrium, both groups propose the same policy, which maximizes the joint welfare of the groups. Therefore there is no rent dissipation at all. A politician trying to maximize lobbying expenditure would always prefer an imperfectly discriminating contest.

\section{Appendix: Proof of lemma 1}

Lemma 1. For group 1 (2) each policy proposal $y_{1}>y^{*}\left(y_{2}<y^{*}\right)$ is strictly dominated by $y^{*}$.

Proof. I prove this lemma for group 1; the proof for group 2 is similar. Fix a $\bar{y}_{1}>y^{*}$. We want to show that $E\left(v_{1}\left(\bar{y}_{1}, y_{2}\right)\right)<E\left(v_{1}\left(y^{*}, y_{2}\right)\right)$ for all $y_{2} \in R$.

Case 1: $y_{2} \leq y^{*}$.

Suppose group 1 proposes $\bar{y}_{1}$. Then both groups prefer the policy proposal of the other group over their own policy proposal. Therefore, in stage two $x_{1}=x_{2}=0$, and $E\left(v_{1}\left(\bar{y}_{1}, y_{2}\right)\right)=\frac{1}{2}\left(u_{1}\left(\bar{y}_{1}\right)+u_{1}\left(y_{2}\right)\right)$.

On the other hand, if group 1 proposes $y^{*}$, both groups still prefer the policy proposal of the other group over their own policy proposals (or are indif-

\footnotetext{
${ }^{8}$ If proposals are exogenous, and the stakes of the lobbyists are asymmetric, an imperfectly discriminating contest sometimes leads to higher expected expenditures and rent dissipation. See (e.g.) Fang (2002).
} 
ferent iff $\left.y_{2}=y^{*}\right)$, and therefore $x_{1}=x_{2}=0$. It follows that $E\left(v_{1}\left(y^{*}, y_{2}\right)\right)=$ $\frac{1}{2}\left(u_{1}\left(y^{*}\right)+u_{1}\left(y_{2}\right)\right)>E\left(v_{1}\left(\bar{y}_{1}, y_{2}\right)\right)$.

Case 2: $y^{*}<y_{2} \leq \bar{y}_{1}$.

As in case 1 , if group 1 proposes $\bar{y}_{1}$ it gets $E\left(v_{1}\left(\bar{y}_{1}, y_{2}\right)\right)=\frac{1}{2}\left(u_{1}\left(\bar{y}_{1}\right)+u_{1}\left(y_{2}\right)\right)$. Notice that $E\left(v_{1}\left(\bar{y}_{1}, y_{2}\right)\right) \leq u_{1}\left(y_{2}\right)$.

If group 1 proposes $y^{*}$ then both groups prefer their own proposals over that of the other group. But since

$$
s_{1}\left(y^{*}, y_{2}\right)-s_{2}\left(y_{2}, y^{*}\right)=u_{1}\left(y^{*}\right)+u_{2}\left(y^{*}\right)-\left(u_{1}\left(y_{2}\right)+u_{2}\left(y_{2}\right)\right)
$$

it follows from the definition of $y^{*}$ that $s_{1}\left(y^{*}, y_{2}\right)>s_{2}\left(y_{2}, y^{*}\right)$. Hence

$$
\begin{aligned}
E\left(v_{1}\left(y^{*}, y_{2}\right)\right) & =s_{1}\left(y^{*}, y_{2}\right)-s_{2}\left(y_{2}, y^{*}\right)+u_{1}\left(y_{2}\right)> \\
& >u_{1}\left(y_{2}\right) \geq E\left(v_{1}\left(\bar{y}_{1}, y_{2}\right)\right) .
\end{aligned}
$$

Case 3. $y_{2}>\bar{y}_{1}$.

Here, if group 1 proposes $\bar{y}_{1}$ it gets (see equation (5))

$$
E\left(v_{1}\left(\bar{y}_{1}, y_{2}\right)\right)=\max \left\{s_{1}\left(\bar{y}_{1}, y_{2}\right)-s_{2}\left(y_{2}, \bar{y}_{1}\right), 0\right\}+u_{1}\left(y_{2}\right) .
$$

From equation (8) it follows that

$$
s_{1}\left(y^{*}, y_{2}\right)-s_{2}\left(y_{2}, y^{*}\right)>\max \left\{s_{1}\left(\bar{y}_{1}, y_{2}\right)-s_{2}\left(y_{2}, \bar{y}_{1}\right), 0\right\}
$$

Therefore,

$$
E\left(v_{1}\left(y^{*}, y_{2}\right)\right)=s_{1}\left(y^{*}, y_{2}\right)-s_{2}\left(y_{2}, y^{*}\right)+u_{1}\left(y_{2}\right)>E\left(v_{1}\left(\bar{y}_{1}, y_{2}\right)\right) .
$$

\section{References}

[1] Aidt, T., 2002, Strategic Political Participation and Redistribution. Economics and Politics 14(1), 19-40. 
[2] Baye, M. R., D. Kovenock and C. G. de Vries, 1993, Rigging the Lobbying Process: An Application of the All-Pay Auction. American Economic Review 83, 289-294.

[3] Baye, M. R., D. Kovenock and C. G. de Vries, 1996, The all-pay auction with complete information. Economic Theory 8, 291-305.

[4] Calvert, R. L., 1985, Robustness of the multidimensional voting model: Candidate motivations, uncertainty, and convergence. American Journal of Political Science 29, 69-95.

[5] Che, Y.-K. and I. Gale, 1997, Rent dissipation when rent seekers are budget constrained. Public Choice 92, 109-126.

[6] Che , Y.-K. and I. Gale, 1998, Caps on political lobbying. American Economic Review 88, 643-651.

[7] Ellingsen, T., 1991, Strategic Buyers and the Social Cost of Monopoly. American Economic Review 81, 648-657.

[8] Epstein, G. S. and S. Nitzan, 2002, The social cost of rent seeking when consumer opposition influences monopoly behavior. European Journal of Political Economy 19, 61-69.

[9] Epstein, G. S. and S. Nitzan, 2003, The struggle over migration policy. Working Paper.

[10] Epstein, G. S. and S. Nitzan, 2004, Strategic Restraint in Contests. European Economic Review 48, 201-210.

[11] Fang, H., 2002, Lottery versus all-pay auction models of lobbying. Public Choice 112, 351-371.

[12] Hillman, A. L. and J. G. Riley, 1989, Politically contestable rents and transfers. Economics and Politics 1, 17-39.

[13] Hirshleifer, J. and J. G. Riley, 1992, The Analytics of Uncertainty and Information (Cambridge UP). 
[14] Konrad, K. A., 2000a, Spatial contests. International Journal of Industrial Organization 18(6), 965-974.

[15] Konrad, K. A., 2000b, Trade contests. Journal of international economics 51, 317-334.

[16] Leidy, M. P., 1994, Rent dissipation through self-regulation: The social cost of monopoly under threat of reform. Public Choice 80: 105-128.

[17] O'Keeffe, M., W. K. Viscusi and R. J. Zeckhauser, 1984, Economic Contests: Comparative Reward Schemes. Journal of Labor Economics $2(1), 27-56$.

[18] Tullock, G., 1975, On the efficient organization of trials. Kyklos 28, 745762 .

[19] Tullock, G., 1980, Efficient rent seeking, in: J. Buchanan, R. Tollison and G. Tullock, eds., Towards a theory of the rent seeking society (College Station: Texas A\&M University Press). 